\title{
Korelasi Karakteristik Peternak Terhadap Tingkat Adopsi Penggunaan Jamu Herbal Pada Budidaya Itik Magelang Pedaging Di Kecamatan Bandongan
}

\section{(The Correlation of Breeder Characteristics to The Adoption Rate in Using Herbal Medicine on Magelang-Duck Cultivation at Bandongan District)}

\author{
Supriyanto, Agung Cahya Budy, Zainal Arifin \\ Politeknik Pembangunan Pertanian Yogyakarta Magelang \\ Jl. Magelang Kopeng km 07 Tegalrejo Magelang Jawa Tengah \\ E-mail : agungcahyabudy@gmail.com
}

Disetujui : 3 Mei 2019

\begin{abstract}
ABSTRAK
Penelitian ini bertujuan untuk mengetahui tingkat adopsi peternak mengenai penggunaan jamu herbal pada budidaya itik magelang pedaging beserta hubungan karakteristik peternak terhadap tingkat adopsi tersebut. Kegiatan ini dilaksanakan tanggal 05 Marethingga 30 April2018di Kecamatan Bandongan Kabupaten Magelang. Responden yang menjadi sampel berjumlah 32 peternakyang dipilihsecara purposive sampling dengan syarat peternak pernah mendapat penyuluhan mengenai jamu herbal serta pernah menggunakan jamu herbal dalam budidaya itik magelang pedaging. Penelitian ini menggunakan metode survei dan desain penelitian deskriptif korelasional untuk mengetahui hubungan karakteristik peternak (umur, tingkat pendidikan, intensitas penyuluhan, pengalaman beternak, jumlah tanggungan keluarga, dan jumlah kepemilikan ternak) terhadap tingkat adopsi peternak. Pengumpulan data menggunakan metode wawancara dan observasi dengan panduan instrumen adopsi. Analisis data menggunakan analisis deskriptif untuk mengetahui tingkat adopsi dan analisis korelasi rank spearman untuk mengetahui arah, tingkat keeratan, dan signifikansi hubungan antara karakteristik peternak terhadap tingkat adopsi. Analisis regresi linear digunakan untuk mendukung hasil analisis korelasi. Hasil penelitian menunjukkan tingkat adopsi peternak berada dalam kategori tinggi. Hubungan antara umur, pengalaman beternak, dan jumlah tanggungan keluarga terhadap tingkat adopsi masing-masing menunjukkan hubungan yang tidak signifikan. Tingkat pendidikan dan intensitas penyuluhan masing-masing mempunyai hubungan yang positif, sedang, dan sangat signifikan terhadap tingkat adopsi, sedangkan jumlah kepemilikan ternak berhubungan positif, sedang, dan signifikan terhadap tingkat adopsi.
\end{abstract}

Katakunci:Korelasi, Karakteristikpeternak, Adopsi, Jamuherbal, Budidaya, Itikmagelang pedaging.

\section{ABSTRACT}

This study aims to know breeders adoption rate in using herbal medicine on Magelang duck cultivation and the correlation of breeder characteristics on that adoption rate. This activity takes place from March $5^{\text {th }}$ to April 302018 in Bandonga district, 
Magelang regency. Thirty two bredeers as the respondents for sample which selected by purposive sampling with requirements are all the breeders had given counseling about herbal medicine and they ever use herbal medicine in magelang duck cultivation. This study used survey method and descriptive correlational research design to know the relationship ofbreedercharacteristics (age, educationlevel, intensity of counseling, breeder experience, number of family dependents, and number of livestock ownership) to the breeder adoption rate. Data collection used interview and observation methods with guidance of adoption instruments. Data analysis used descriptive analysis to know adoption rate and corellation analysis rank spearman to know the direction, level of closeness, and significance of relationship between breeder characteristics to adoption rate. Linear regression analysis is used to support the results of correlation analysis. The results showed the adoption rate of breeders are in high category. Each relationship between age, breeder experience, and the number of family dependents on adoption rate showing insignificant relationship. While the level of education and intensity counseling each have a very significant relationship to the rate of adoption, and the number of livestock ownership is significantly related to the adoption rate.

Keywords : Correlation, Characteristics of breeder, Adoption, Herbal medicine, Cultivation, Magelang duck.

\section{PENDAHULUAN}

\section{Latar Belakang}

Pemahaman tentang adopsi serta teknik pengukurannya akan bermanfaat memberikan gambaran riel tentang kadar perhatian petani terhadap inovasi teknologi pertanian. Informasi itu penting untuk dijadikan sebagai dasar pertimbangan pengambilan keputusan dalam pembinaan petani ke depan. (Hendayana, 2014).

Hasil identifikasi, bahwa di wilayah Kecamatan Bandongan pernah dilaksanakan penyuluhan dan pelatihan pembuatan jamu herbal untuk ternak, tepatnya di KTNA Kecamatan Bandongan dan KUB Bina Karya baik oleh penyuluh swadaya, dinas pertanian maupun oleh penyuluh BPPKKecamatan.

Kegiatan penelitian terhadap peternak mengenai tingkat adopsi penggunaan jamuherbal padabudidaya itik di Kecamatan Bandongan perlu dilakukan untuk mengetahui sejauh mana tingkat adopsi terhadap inovasi teknologi dibidang penggemukan itik magelang pedaging serta korelasinya dengan karakteristik peternak disana. Hasilnya diharapkan dapat digunakan sebagai gambaran tingkat adopsi peternak khususnya peternak itik pedaging di Kecamatan Bandongan.

\section{Perumusan Masalah}

Rumusan masalah dalam penelitian ini yaitu :

1. Belum diketahui tingkat adopsi peternak itik Kecamatan Bandongan mengenai penggunaan jamu herbal padabudidayaitikmagelang pedaging.

2. Belum diketahui korelasi karakteristik peternak (umur, pendidikan formal, intensitas penyuluhan, pengalaman beternak, jumlah tanggungan keluarga, dan jumlah kepemilikan ternak) terhadap tingkat adopsi peternak 


\section{Tujuan Penelitian}

1. Mengetahui tingkat adopsi peternak itik Kecamatan Bandongan mengenai penggunaan jamu herbal pada budidaya itik magelang pedaging.

2. Mengetahui korelasi karakteristik peternak (umur, pendidikan formal, intensitas penyuluhan, pengalaman beternak, jumlah tanggungan keluarga, dan jumlah kepemilikan ternak) terhadap tingkat adopsi peternak.

\section{LANDASAN TEORI}

Rogers dan Shoemaker (1971) dalam Brahmana (2011) mengatakan adopsi adalah proses mental, dalam mengambil keputusan untuk menerima atau menolak ide baru dan menegaskan lebih lanjut tentang penerimaan dan penolakan ide baru tersebut. Menurut Ibrahim, dkk. (2003) dalam Putri (2014) adopsi adalah proses yang terjadisejak pertama kali seseorang mendengar hal baru sampai orang tersebut mengadopsi (menerima, menerapkan, menggunakan) hal baru tersebut. Petani mengambil keputusan setelah melalui beberapa tahapan adopsi.

\section{Faktor Karakteristik Peternak}

- Umur $\left(x_{1}\right)$

- Tingkat Pendidikan $\left(x_{2}\right)$

- Intensitas penyuluhan $\left(x_{3}\right)$

- Pengalaman beternak $\left(x_{4}\right)$

- Jumlah tanggungan keluarga $\left(x_{5}\right)$

- Jumlahkepemilikanternak $\left(x_{6}\right)$
Mardikanto (2009) menyatakan bahwa proses adopsi melalui tahapantahapan yakni : a) Awareness atau kesadaran yaitu sasaran mulai sadar tentang adanya inovasi yang ditawarkan oleh penyuluh. b). Interest tumbuhnya minat. c) Evaluation atau penilaian terhadap baik/buruk atau manfaat inovasi yang telah diketahui informasinya secara lebih lengkap. d) Trial atau mencoba dalam skala kecil untuk lebih meyakinkan penilaiannya. e) Adoption atau menerima/ menerapkan dengan penuh keyakinan berdasarkan penilaian dan uji coba yang telah dilakukan dan diamatinya sendiri.

Menurut Soekartawi (2008) adopsi inovasi bagi seorang peternak berkaitan dengan karakteristik peternak yaitu umur, tingkat pendidikan, jumlah tanggungan keluarga, serta intensitas penyuluhan yang diterima. Menurut Putri (2014) petani memiliki karakteristik yang beragam, yang berupa karakter demografis, karakter sosial serta karakter kondisi ekonomi petaniitu sendiri. Karakteristik ini meliputi umur, tingkat pendidikan, jenis kelamin, dan luas lahan. Kerangka pikir kegiatan penelitian ini seperti pada Gambar 1 berikut.

Gambar 1. Kerangka pikir 
Berdasarkan landasan teori dan kerangka pikir dapat dirumuskan hipotesis dari kegiatan penelitian ini sebagai berikut.

1. Diduga, tingkat adopsi peternak itik Kecamatan Bandongan mengenai penggunaan penggunaan jamu herbal pada budidaya itik magelang pedaging berada pada kategori "Tinggi".

2. Diduga ada korelasi yang signifikan antara masing-masing faktor karakteristik peternak (umur, tingkat pendidikan, intensitas penyuluhan, pengalaman beternak, jumlah tanggungan keluarga, dan jumlah kepemilikan ternak) terhadap tingkat adopsi penggunaan jamu herbal pada budidaya itik magelang pedaging di Kecamatan Bandongan.

\section{METODOLOGI}

\section{Waktu dan Tempat}

Kegiatan penelitian telah dilaksanakan mulai tanggal 05 Maret 2018 hingga tanggal 30 April 2018 di Kecamatan Bandongan, Kabupaten Magelang, Provinsi Jawa Tengah.

\section{Alat dan Bahan}

Alat yang digunakan yaitu : instrumen evaluasi, proyektor, laptop, folder, presentasi powerpoint, alat pembuatan jamu herbal, serta kamera handphone. Bahan yang diperlukan yaitu: kuesioner, kertas HVS A4 80 gr sebanyak 2 rim, sertabahan pembuatan jamu herbal.

\section{Rancangan Penelitian}

Metode digunakan dalam penelitian ini adalah metode survei, dengan desain penelitian deskriptif korelasional. Deskriptif korelasional merupakan penelitian yang diarahkan unuk menjelaskan hubungan antara variabel bebas dan variabel terikat, yaitu karakterisitk peternak terhadap tingkat adopsipeternak.

\section{Populasi dan Sampel}

Populasi yang digunakan dalam kajian ini yaitu peternak itik di wilayah Kecamatan Bandongan yang memelihara itik pedaging, Penarikan sampel menggunakan teknik purposive sampling dengan ketentuan peternak pernah menggunakan jamu herbal pada budidaya itik magelang pedaging. Sampel yang digunakan sebanyak 32 peternak yang terdiri dari anggota KUB Bina Karya dan anggotaKTNAKecamatanBandongan.

\section{Data dan Sumber Data}

Data yang diperlukan dalam kajian ini yaitu data primer dan data sekunder. Data primer dikumpulkan melalui wawancara dan observasi. Cara pengambilan data primer dengan teknik anjangsana serta melakukan observasi secara partisipatif. Data sekunder diperoleh dari monografi Kecamatan Bandongan maupun data-data yang sudah tersedia di instansi terkait seperti BPPK Kecamatan Bandongan.

\section{Analisis Data}

Tingkat adopsi petani dianalisis menggunakan analisis deskriptif dengan bantuan garis kontinum/ garis interval (rating scale) berdasarkan kaidah skala likert. 
Analisis korelasi karakteristik peternak terhadap tingkat adopsi menggunakan analisis Rank Spearman. Analisis regresi linear sebagai analis pendukung analisis korelasi Rank Spearman untuk mengetahui besarnya pengaruh karakteristik peternak terhadap tingkat adopsi.

\section{Pengabdian Masyarakat}

Kegiatan pengabdian masyarakat telah dilaksanakan di Kelompok Tani Jaya Desa Tonoboyo Kecamatan Bandongan

dalam bentuk penyuluhan dan pemberdayaan posluhdes. Materi yang disuluhkan dalam kegiatan pengabdian ini yaitu penggunaan jamu herbal dalam budidaya itik magelang pedaging.

\section{HASIL DAN PEMBAHASAN}

\section{Tingkat Adopsi Peternak}

Hasil penelitian menunjukkan bahwa tingkat adopsi peternak diperoleh rata-rata skor responden 65,59 yang berada pada kategoti tinggi seperti pada Gambar 2.

\section{9,59}

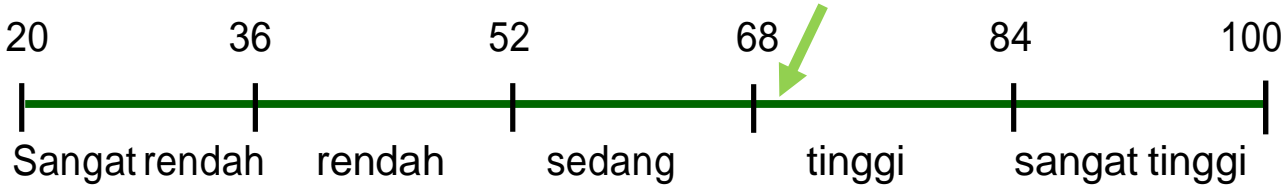

Gambar 2. Garis kontinum tingkat adopsi peternak di Kecamatan Bandongan

Tingginya tingkat adopsi peternak kemungkinan dipengaruhi oleh beberapa faktor antara lain karakteristik inovasi, karakteristik peternak, peranan penyuluh dalam menyampaikan inovasi kepada sasaran, serta media penyuluhan yang digunakan. Sejalan dengan pendapat Mardikanto (2009) bahwa tingkat adopsi dipengaruhi oleh banyak faktor, yaitu : 1) sifat-sifat atau karakteristik inovasi, 2) sifatsifat atau karakteristik calon pengguna, 3) pengambilan keputusan adopsi, 4) media yang digunakan, 5) kualifikasi penyuluh dan 6) sumber informasi.

Tingginya tingkat adopsi dapat disebabkan karena inovasi jamu herbal memiliki keuntungan dibandingkan dengan growth promotor pabrikan yang dulu dipakai yang memiliki banyak dampak buruk bagi kesehatan. Pendapat ini didukung oleh Kotler dan Keller (2013) keuntungan relatif adalah tingkat dimana inovasi tampak lebih bagus dari produk lama.. Biasanya diukur dari segi ekonomi, prestasi sosial, kenyamanan dan kepuasan. Semakin besar keuntungan relatif yang dirasakan oleh adopter, maka semakin cepat inovasi tersebut diadopsi.

Metode pumbuatan dan aplikasi jamu herbal cukup mudah dan dapat dibuat oleh siapa saja kemungkinan juga salah satu faktor yang menyebabkan tingkat adopsi teknologi tersebut menjadi tinggi. Sesuai dengan pendapat Kotler dan Keller (2013) bahwa kompleksitas adalah tingkat sulitnya inovasi untuk dipahami atau digunakan. Tingkat kerumitan dari suatu inovasi untuk diadopsi, seberapa sulit memahami dan menggunakan inovasi. Semakin mudah suatu inovasi dimengerti dan dipahami oleh adopter, maka semakin cepat inovasi diadopsi. 
Tingkat pendidikan kemungkinan akan mempengaruhi tingkat pengetahuan peternak, sehingga apabila tingkat pendidikan tinggi, pengetahuan kemungkinan akan tinggi juga sehingga proses penerapan inovasi teknologi lebih cepet. Sehingga dapat menyebabkan tingkat adopsi menjadi tinggi. Sesuai pendapat Sidauruk dkk. (2015) bahwa tingkat pendidikan formal yang dimiliki petani akan memperlihatkan tingkat pengetahuan serta wawasan petani itu sendiri, dimana pada akhirnya akan mempengaruhi para petani dalam mengadopsi teknologi yang tepat dalam kegiatan usahatani mereka nantinya.

Intensitas penyuluhan yang semakin sering diprediksi dapat mempercepat proses adopsi sehingga adopsi menjadi tinggi. Tingginya tingkat adopsi karena informasi atau inovasi yang disampaikan kepada peternak akan lebih cepat dipahami. Semakin sering mendapat penyuluhan akan semakin cepat menguasai materi. Sejalan dengan pernyataan Sumbayak (2006) dalam Sikombong (2014) bahwa semakin tinggi mengikuti frekuensi penyuluhan maka keberhasilan penyuluhan pertanian yang disampaikan semakin tinggi pula. Frekuensi petani dalam mengikuti penyuluhan yang meningkat disebabkan karena penyampaian yang menarik dan tidak membosankan serta yang disampaikan benar-benar bermanfaat untuk usaha taninya.

\section{Korelasi Karakteristik Peternak Terhadap Tingkat Adopsi}

Hasil analisis menggunakan korelasi rank spearman ditampilkan pada Tabel 1 berikut :

Tabel 1. Hasil analisis korelasi Rank Spearman.

\begin{tabular}{lrr}
\hline Karakteristik Peternak & Koefisien Korelasi & Sig. (2-tailed) \\
\hline Umur & .098 & .593 \\
Tingkat Pendidikan & .515 & .003 \\
Intensitas Penyuluhan & .474 & .006 \\
Pengalaman Beternak & .205 & .261 \\
Jumlah Anggota Keluarga & .253 & .163 \\
Jumlah Kepemilikan Ternak & .394 & .026 \\
\hline
\end{tabular}

Sumber : Hasil analisis korelasi Rank Spearman

Umur

Hasil penelitian menunjukkan tidak ada hubungan nyata antara umur dengan tingkat adopsi peternak. Dimungkinkan peternakyang lebih tua lebih tinggitingkat pendidikannya, memiliki itik lebih banyak, atau lebih banyak menerima penyuluhan. Pendapat tersebut sejalan dengan hasil penelitian Utama, dkk., (2014) yang menjelaskanbahwavariabelumurbukanlah variabel yang menentukan tingkat adopsi teknologi oleh petani. Sebagian besar petani telah cukup lama melakukan usaha sehingga memiliki waktu yang cukup lama untuk meningkatkan penerapan paket teknologi yang dianjurkan melalui proses difusi. 
Umur tidak berhubungan dengan tingkat adopsi diduga karena teknologi jamu herbal ini dapat diterapkan oleh semua kalangan umur karena proses pembuatannya tidak memerlukan keterampilan khusus. Jadi peternak muda atau tua dapat menerapkan teknologi tersebut dengan mudah. Hasil penelitian ini sejalan dengan penelitian yang dilakukan oleh Utama, dkk. (2014) bahwa pada taraf kepercayaan $95 \%$, tidak ada hubungan yang nyata antara umur dengan tingkat adopsi petani pada teknologi karena adopsi teknologi dapat diterapkan oleh siapa saja tanpa membedakan umur.

\section{Tingkat Pendidikan}

Korelasi antara tingkat pendidikan dengan tingkat adopsi peternak jika dilihat dari keeratan menunjukkan hubungan yang sedang $(r=0,515)$. Hal tersebut diduga disebabkan karena mayoritas peternak berpendidikan SLTA, sehingga keeratan hubungan antara tingkat pendidikan dan tingkat adopsi sedang. Diduga terdapat hubungan antara tingkat pendidikan dengan tingkat adopsi peternak karena peternak yang berpendidikan tinggi cenderung sudah mempelajari tentang peternakan lebih mendalam daripada peternak dengan pendidikan rendah. Sesuai dengan pendapat Sikombong (2014) bahwa peternak yang memiliki jenjang pendidikan yang tinggi telah banyak mempelajari bagaimana pemeliharaan ternak yang baik serta meningkankan produktifitas ternak melalui pakan yang diberikan. Pendidikan yang tinggi yang dimiliki peternak dapat mempercepat proses adopsi inovasi serta penggunaan teknologi.
Tingkat pendidikan berhubungan sangat signifikan terhadap tingkat adopsi. Peternak dengan pendidikan tinggi kemungkinan cenderung lebih cepat dalam mengadopsi teknologi dibandingkan peternak yang berpendidikan rendah karena peternak yang berpendidikan tinggi lebih kreatif dan lebih cepat menangkap inovasi jamu herbal. Menurut Sumbayak (2006) dalam Putri (2014) bahwa salah satu faktor yang menyebabkan seorang peternak berbeda dalam hal menerima inovasiadalah tingkat pendidikan yang dimiliki, semakin cepat dalam menyerap inovasi dan berdampak positif terhadap usaha yang dijalankannya.

\section{Intensitas Penyuluhan}

Intensitas penyuluhan memiliki hubungan yang sangat signifikan terhadap tingkat adopsi. Intensitas penyuluhan ratarata 3-4 kali per bulan dimana penyuluhan yang semakin sering diterima diprediksi dapat mempercepat proses adopsi karena informasi atau inovasi yang disampaikan kepada peternak akan lebih cepat dipahami. Semakin sering mendapat penyuluhan akan semakin cepat menguasai materi. Sejalan dengan pernyataan Sumbayak dalam Sikombong (2014) bahwa semakin tinggi mengikuti frekuensi penyuluhan maka keberhasilan penyuluhan pertanian yang disampaikan semakin tinggi pula. Frekuensi petani dalam mengikuti penyuluhan yang meningkat disebabkan karena penyampaian yang menarik dan tidak membosankan serta yang disampaikan benar-benar bermanfaat untuk usaha taninya. 


\section{Pengalaman Beternak}

Tidakterdapathubungan yang nyata antara pengalaman beternak dengan tingkat adopsi. Pengalaman beternak ratarata 1-10 tahun namun pengalaman beternak yang lama tidak menjamin menyebabkan tinggi dalam mengadopsi inovasi, diduga karena peternak cenderung lebih percaya terhadap kebiasaanturuntemurun dari nenek moyangnya dulu daripada teknologi baru yang belum terbukti keunggulannya. Sidauruk (2015) menerangkan bahwa tidak ada hubungan yang signifikan antara lama bertani terhadap tingkat adopsi petani terhadap teknologi budidaya jagung. Lama bertani ternyata tidak menjamin seorang petani untuk mengadopsi suatu teknologi.

Dimungkinkan hal ini dikarenakan pengalaman beternak sebagian besar masih menggunakan cara yang konvensional secara turun-temurun dari nenek moyang dan telah menjadi kebiasaan sehingga belum menggunakan inovasi teknologi. Terlebih lagi apabila teknologi tersebut belum dibuktikan dihadapan peternak secara langsung. Sesuai dengan penelitian Utama, dkk., (2014) yang mana dalam penelitiannya pada taraf kepercayaan $95 \%$ tidak terdapat hubungan yang nyata antara variabel pengalaman berusahatani padi dengan tingkat adopsi petani pada teknologi. Selain itu kerena kegiatan usahatani dilakukan secara turun temurun, sehingga petani sudah mempunyai konsep atau cara tersendiri dalam berusahatani. Sedangkan teknologi baru yang belum terbukti menyebabkan petani cenderung tidak langsung menerapkan.

\section{Jumlah Tanggungan Keluarga}

Tidak terdapat hubungan antara jumlah tanggungan keluarga terhadap tingkat adopsi peternak. Hal ini diduga karena banyak sedikitnya tanggungan keluarga tidak berdampak pada tingkat adopsi peternak namun lebih mengarah kepada pendapatan dan ekonomi keluarga. Hasil ini sejalan dengan penelitian Sidauruk dkk., (2015) bahwa dalam penelitiannya faktor jumlah tanggungan keluarga tidak berpengaruh signifikan terhadap tingkat adopsi petani terhadap suatu teknologi. Jumlah tanggungan keluarga tidak menentukan adopsi inovasi tetapi berhubungan dengan pendapatan dan perekonomian keluarga.

\section{Jumlah Kepemilikan Ternak}

Jumlah kepemilikan ternakmemiliki hubungan yang signifikan terhadap tingkat adopsi. Peternak yang memiliki banyak ternak kemungkinan lebih cepat dalam menerima inovasi karena peternak sudah berorientasi agribisnis yang selalu mencoba teknologi-teknologi yang paling efisien agar usahanya menguntungkan. Pendapat ini didukung oleh Bachri (2016) yang berpendapat bahwa, petani yang mempunyai lahan yang luas ataujumlah ternak banyak akan lebih mudah mengadopsi inovasi daripada petani yang berlahan sempit atau jumlah ternak sedikit, hal ini disebabkan tingkat efisien penggunaan saranaproduksi.

Diduga terdapat hubungan yang signifikan antara jumlah kepemilikan ternak terhadap tingkat adopsi karenapeternak yang memiliki banyak itik akan lebih berbicara pada efisiensi sehingga segala 
inovasi atau hal baru akan dicoba untuk diterapkan. Pendapat ini didukung oleh Rogers dan Shoemaker (1971) dalam Suryawan, dkk., (2016) yang mengatakan bahwa petani ternak yang mempunyai ternak lebih banyak akan lebih cepat menerima ide-ide baru, sehingga tingkat adopsi akan semakin baik. Hal ini dikarenakan peternak tersebut tidak mampu untuk mengontrol semua ternak yang dimilikinya, serta peternaktersebut sudah menggunakan tenaga kerja untuk memelihara semua ternakyang dimilikinya.

\section{SIMPULAN DAN SARAN}

\section{Simpulan}

Hasil penelitian sosial korelasi karakteristik peternak terhadap tingkat adopsi penggunaan jamu herbal pada budidaya itik magelang pedaging di Kecamatan Bandongan dapat disimpulkan bahwa Tingkat adopsi peternak termasuk dalam kategori tinggi. Hubungan antara umur, pengalaman beternak, dan jumlah tanggungan keluarga terhadap tingkat adopsi masing-masing menunjukkan hubungan yang tidak signifikan. Tingkat pendidikan dan intensitas penyuluhan masing-masing mempunyai hubungan yang positif, sedang, dan sangat signifikan terhadap tingkat adopsi, sedangkan jumlah kepemilikan ternak berhubungan positif, sedang, dan signifikan terhadap tingkat adopsi.

\section{Saran}

Hasil penelitian ini diharapkan dapat digunakan sebagai gambaran penyuluh Kecamatan Bandongan dalam mengambil langkah dan kebijakan terutama dalam hal penyuluhan dibidang peternakan. Diharapkan penelitian yang lebih detail mengenai karakteristik dan tingkat adopsi peternak di kecamatan bandongan demi hasil yang lebih mendalam.

\section{DAFTAR PUSTAKA}

Bachri. 2016. Faktor-Faktor yang Mempengaruhi Adopsi Inovasi Teknologi Oleh Petani Padi Sawah Di Desa Kolam Kecamatan Percut Sei Tuan Kabupaten Deli Serdang. Universitas Medan Area Medan. Medan.

Brahmana, M. B. 2011. Pengaruh Kompatibilitas Terhadap Keputusan Adopsi Ide Dan Alat Kontrasepsi Keluarga Berencana Pria Di Kalangan Pegawai Negeri Sipil Badan Pemberdayaan Perempuan Dan Keluarga Berencana Kota Medan. Tesis. Program Studi S2 Fakultas Kesehatan Masyarakat Universitas Sumatera Utara. Medan.

Hendayana, R. 2014. Persepsi dan Adopsi

Teknologi Teori dan Praktik Pengukuran. Balai Besar Pengkajian dan Pengembangan Teknologi Pertanian. Bogor

Kotler, P., dan K. L. Keller. 2013. Marketing Management : Fourteenth Edition, New Jersey: Prentice-Hall Inc.

Mardikanto, T. 2009. Sistem Penyuluhan Pertanian. Sebelas Maret University Press, Surakarta.

Putri, A. Z. 2014. Pengaruh Karakteristik Peternak Terhadap Kecepatan Adopsi Usaha Ayam Broiler Di 
Kecamatan Bontoharu, Kabupaten Kepulauan Selayar Jurusan Sosial Ekonomi Peternakan Fakultas Peternakan Universitas Hasanuddin. Makassar.

Sidauruk, V.M., G. Rahmanta, Emalisa. 2015. Analisis Tingkat Adopsi Petani Terhadap Teknologi Budidaya Jagung Dan Hubungannya Dengan Faktor Sosial Ekonomi. Fakultas PertanianUSU. Sumatera Utara.

Sikombong, I. 2014. Skripsi: Pengaruh Karakteristik Peternak Terhadap Adopsi Pemanfaatan Limbah Tanaman Pangan Sebagai Pakan Ternak Sapi Potong Di Desa Samangki Kecamatan Simbang Kabupaten Maros. Fakultas Peternakan Universitas Hasanuddin. Makassar.
Soekartawi. 2008. Prinsip Dasar Komunikasi Pertanian. UI Press. Jakarta.

Suryawan, I. G. M., G. Suarta, N. W. T. Inggriati. 2016. Faktor-Faktor Yang Mempengaruhi Tingkat Adopsi Sapta Usaha Peternakan Babi Kemitraan Pt. Charoen Phokphand Di Bali. Fakultas Peternakan, Universitas Udayana. Denpasar. Utama S.P., Indra C., Rahmad J. 2014. Faktor-Faktor Yang Berhubungan Dengan Tingkat Adopsipetani Pada Teknologi Budidaya Padi Sawah Sistem Legowo Di Kelurahan Dusun Besar Kecamatan Gading Cempaka Kota Bengkulu. Jurnal ISSN 14121837. Fakultas Pertanian UNIB. Bengkulu. 